\title{
Adjunct role labeling for Russian
}

\author{
Roman Kazakov \\ National Research University \\ Higher School of Economics \\ Moscow, Russia \\ roman-k2000@mail.ru
}

\author{
Olga Lyashevskaya \\ National Research University \\ Higher School of Economics; \\ V. V. Vinogradov Russian Language \\ Institute of RAS \\ Moscow, Russia \\ olesar@yandex.ru
}

\begin{abstract}
The task of the semantic role labeling usually focuses on identifying and classifying the core, obligatory arguments of the predicate. The adjuncts of Time, Location, etc. (non-core, modifier arguments) are considered on the periphery of the task [30] and even doing the easy part of it [44], despite the fact that they are highly integrated into the clause structure and may non-trivially interact with the meaning of the verb $[4,32]$. In this paper, we present experiments on labeling the adjunct roles of LOCATION, TIME, MANNER, DEGREE, REASON, and PURPOSE, based on the manually annotated Adjuncts-FrameBank data set. The results show an average F1-score of 0.94 on the gold adjunct phrase annotations using the word2vec representations of adjuncts, word2vec representations of predicates, and the moprhosyntactic marking of adjuncts. Our findings generally corroborate the theoretical hypothesis on the structural and semantic autonomy and lexico-morphosyntactic specialization of adjuncts. Yet, more complicated organization of their network is revealed, pointing to the diversity of adjuncts in terms of their distribution and behavior.
\end{abstract}

Keywords: semantic role labeling, adjunct role labeling, adjunct and predicate embeddings, Russian FrameBank, Russian language

DOI: $10.28995 / 2075-7182-2021-20-367-377$

\section{Определение семантических ролей сирконстантов для русского языка}

\author{
Роман Казаков \\ НИУ Высшая Школа \\ Экономики \\ Москва, Россия \\ roman-k2000@mail.ru
}

\author{
Ольга Ляшевская \\ НИУ Высшая Школа \\ Экономики; \\ Институт русского языка \\ им. В. В. Виноградова РАН \\ Москва, Россия \\ olesar@yandex.ru
}

\begin{abstract}
Аннотация
Задача разметки семантических ролей (semantic role labeling, SRL), как правило, строится вокруг идентификации и классификации ядерных, обязательных аргументов предиката. Сирконстанты времени, места и т. п. (неядерные, модифицирующие аргументы предиката) вытеснены на периферию [30] и даже признаются составляющими самую простую часть задачи [44]. Вместе с тем, они глубоко интегрированы в структуру клаузы и могут нетривиально взаимодействовать со значением глагола $[4,32]$. В этой статье мы представляем эксперименты по определению роли сирконстантов МЕСТА, ВРЕМЕНИ, ОБРАЗА ДЕЙСТВИЯ, СТЕПЕНИ, ПРИЧИНЫ и ЦЕЛИ, на основе аннотированного вручную набора данных Adjuncts-FrameBank. Модель на основе признаков word2vec репрезентаций сирконстантов и предикатов и морфосинтаксического оформления сирконстантов показывает среднюю F1-меру 0,94 на данных, в которых вручную размечены границы предикатов, актантов и сирконстантов. Наши результаты в целом подтверждают теоретические предположения о структурной и семантической автономии и лексико-морфосинтаксической специализации адъюнктов. Тем не менее, обнаруживается более сложная организация их структуры, что указывает на разнообразие адъюнктов с точки зрения их распределения и поведения.

Ключевые слова: классификация семантических ролей, определение семантических ролей сирконстантов, векторные представления сирконстантов и предикатов, ФреймБанк, русский язык
\end{abstract}




\section{Introduction}

Adjunct role labeling is a sub-task of semantic role labeling (SRL) that addresses the identification and classification of the non-core arguments of a predicate. Among semantic roles that communicate "Who does What to Whom and Why and How and When and Where?", Who and What are the core arguments that are defined and constrained by the semantics and governing properties of the particular predicate, while other elements (adjuncts) are less strongly associated, functionally and formally, with it. One can assume that any event takes place in a certain setting, namely, Location and Time, may be explained by a certain Purpose, Reason, or Condition, and may be characterised by aspects such as Frequency, Manner, Measure, Evaluation, or Modality. As the non-core arguments are not necessary to complete the meaning of the predicate, they tend to occur only sporadically in the phrase and thus are considered semantically and syntactically non-obligatory (circumstances in Tesnière's terms [47]).

At the same time, both formal and functional schools claim that adverbs and other non-core arguments have their own selectional and structural preferences, are highly integrated into the structure of the verb phrase and may non-trivially interact with the predicate semantics and grammar, as well as with the verb phrase structure in general and other adjuncts $[14,9,5,27,4,10,16,17]$.

Over the past twenty years the task of SRL was mainly focused on detecting and labeling the obligatory arguments, overshadowing adjuncts, their essence and types. In most analyses, any information about adjuncts is omitted or briefly mentioned. Our study, by contrast, narrowly addresses the distributional properties of adjuncts as a guide to build feature-based labelers for their semantic roles in the verb phrase.

Somewhat simplifying, the task of the adjunct role labeling in a sentence can be subdivided into three subtasks:

1. whether or not the element $\mathrm{A}$ and the predicate $\mathrm{P}$ are related;

2. whether or not $\mathrm{A}$ is an adjunct of $\mathrm{P}$;

3. of which particular type this adjunct relation is.

This paper concerns the third subtask, assuming that (1) and (2) are identified correctly. We frame adjunct classification as a supervised one-of-N classification problem. Specifically, we investigate what kind of linguistic information about the form and meaning of adjuncts and verbs is relevant to the identification of the adjunct roles.

\section{Related works}

SRL as a computational linguistic task has become widespread since the active development of machine learning. The pioneering work of Gildea and Jurafsky [12] used supervised machine learning to predict semantic roles in English FrameNet [3], with syntactic features having the most discriminative power. Since then, a variety of methods has been applied to SRL and SRI (semantic role induction): global optimisation [11], semi-supervised learning [11], and unsupervised learning and graph similarity [20]. More recently, various neural architectures have been found effective for the task [22, 24, 7, 46, 28].

As regards the SRL for Russian, Dialing [43], ETAP3 [13] and Compreno [45] should be mentioned among the early applications. For example, Dialing was based on the method of full variants and rules. [41] combined the dictionary-based approach with a data-driven transition-based model trained on the automatically enriched SynTagRus treebank.

After the SRL-labeled resource Russian FrameBank was published [15, 26], a number of supervised methods were evaluated on it. [18, 19] suggested an SVM-based labeling model that used hand-crafted features extracted from corpus including syntactic features and clustered lexicon. [42] combined information available in annotations (morphosyntactic features of arguments, lemmas of predicates, syntactic labels of arguments, relative positions of arguments) with the word2 $\mathrm{vec}$ embeddings of arguments and predicates. [36] used Bi-GRU and attention to extract the potential features of arguments and then voting ensemble over three models that took both extracted and basic features. In order to overcome biases and scarcity in available annotated data, [37] suggested using the pretrained contextual embeddings and introduced two models to process the argument structures of known and unknown predicates. [1] extended [37] approach with cross-lingual transfer learning and showed that pretraining on English FrameNet slightly improves the results. 
One more SRL resource for Russian was presented recently — PropBank [33], but it is not in use for now, because of its small size.

Nevertheless, the large amount of work on SRL doesn't change the fact that adjuncts are nowhere in sight for researchers. Unfortunately, they are rarely mentioned or even classified. The article of [30] can serve as a weak counterexample: adjuncts were classified into preposition phrases and adverbs. Perhaps, the reason for such a strange bypassing of adjuncts is somewhere in their nature. More detailed and deep work on adjuncts was performed in the article of [44], based on Chinese PropBank data [29]. Along with core arguments authors consider different non-core ones (arguments-modifiers): location, temporal, condition, frequency etc. Their classification architecture was based on the SVM method. One more system that works with adjuncts is Compreno model [6], but it does not distinguish core arguments and adjuncts because of another development purposes: it tries to translate a phrase in a natural language to the universal language, so the type of the valency is not important in this scope. This model is applied mainly in automatic translation. However, this model involves the structure of slots' levels where circumstantial valencies are at the higher levels and actant valencies are at the lower ones [31].

Some works are focused on automatic systems for the identifying of specifically temporal $[38,25]$ or locative [39] relationships.

\section{Theoretical background}

The main distinction between arguments and adjuncts lies in their relations with predicates that are called valencies [47]. Valencies are divided into two types: semantic and syntactic. Semantic valencies are those valencies of the word which attach syntactically dependent words to it, and each of them corresponds to the variable in the interpretation of the word's meaning [2]. Syntactic valencies are capacities to enter in syntactic connections with other elements [23]. Y. Testelets proposes a simple table to understand the difference between arguments and adjuncts (Table 1) [48].

Table 1. The correlation of valency types and core arguments / adjuncts [48]

\begin{tabular}{|c|c|c|}
\hline & Semantic valency & Syntactic valency \\
\hline core arguments & + & + \\
\hline adjuncts & - & + \\
\hline
\end{tabular}

Consequently, core arguments fill in the semantic valency of a predicate while adjuncts do not. In other terms, (core) arguments are called binding valencies of the predicate, while adjuncts - non-binding ones. There are no ideal criteria differentiating between arguments and adjuncts distinction and there is a vast theoretical literature on borderline cases between non-obligatory core valency roles and circumstances [32, 21]. Plungian and Rakhilina suggest the criterion of the compatibility control: 1) a binding valency manifests itself in the relevant compatibility of the predicate; if it does not, there are two outcomes: there is not such a variable in the semantic representation of the predicate or, in rare cases, there are some rules that prohibit its usage; 2 ) the compatibility of the relevant binding valency is «non-trivial». It means that adjuncts may be used with «any» predicate, but, apparently, this does not hold empirically.

Note that compatibility frequently depends on the semantic types of adjuncts, which are not a heterogeneous class. There are different classifications of adjuncts [9]. Classes in them are more or less stable (for example, temporal adjunct can be found in all of them). For our pilot study, we used data in which predicates, core arguments and adjuncts are manually labelled. It will be described in the next section.

\section{Data set}

Russian FrameBank includes examples from the Russian National Corpus in which the verb predicates and their core arguments map to the dictionary of the verb constructions. Non-core elements which semantically relate to the verb but do not correspond to the argument slots in the dictionary are labelled as adjuncts, matrix predicates, or modal elements. Adjuncts include adverbs and particles, prepositional phrases, case phrases, subordinate clauses, infinitive and gerundive verb phrases for the most part, which can be either syntactically dependent on or independent of the predicate. 
Table 2. Some data set strings

\begin{tabular}{|l|l|l|l|}
\hline Phrase & Form & Role & KeyLexeme (predicate) \\
\hline сильно ('hard, really') & ADV & DEGREE & беспокоить ('to bother') \\
в редакции ('in the editorial office') & в ('in') + S.LOC & PLACE & брать ('to take') \\
на ходу ('on the move') & на('on') + S.LOC & MANNER & менять ('to change') \\
$\ldots$ & $\ldots$ & $\ldots$ & $\ldots$ \\
\hline
\end{tabular}

Only the pairs of adjuncts and the corresponding verb predicates were taken to compile the AdjunctsFramebank data set. Each line (e. g. Table 2) represents an adjunct, its form, its type, and a predicate. A form can be a part of speech (e.g. ADV - an adverb), a part of speech and morphosyntactic tag (e.g. V.INF - a verb in infinitive), or a more complex structure ( $3 a+$ S.ACC $\partial o+$ S.GEN - a prepositional phrase (PP) in the accusative case with the preposition 3 ('over') that governs another PP with the preposition $\partial o$ ('before')). Adjuncts can be sentential and of any length (17\% groups has length greater than 3), there are not any restrictions on their form.

Some types (explications) assigned to adjuncts in FrameBank were combined to further simplify classification (Table 3). It was decided to divide adjuncts into six groups: PLACE, TIME, MANNER, DEGREE, PURPOSE, REASON. After aggregating and cleaning, the data set includes 7860 adjunct-verb entries (976 unique verbs, 2819 unique adjuncts).

Table 3. Comparison of the FrameBank classes of adjuncts and generalized classes used in the model

\begin{tabular}{|l|c|l|l|l|}
\hline Generalized class & Frequency, \% & FrameBank class & Frequency, \% & Example \\
\hline PLACE & 12.06 & PLACE & 10.13 & в огороде ('in the garden') \\
& & FINAL POINT & 1.27 & в Госдуму ('to the state Duma') \\
& & INITIAL POINT & 0.33 & отсюда ('from here') \\
& & DISTANCE & 0.33 & издали ('from afar') \\
\hline TIME & \multirow{2}{*}{ (2.02 } & DURATION & 12.25 & долго ('for a long time') \\
& & TIME & 10.99 & вчера ('yesterday') \\
& & FREQUENCY & 8.62 & порой ('sometimes') \\
& & MOMENT OF TIME & 0.1 & в этот час ('at this hour') \\
& & TIME - LIMIT & 0.07 & по сей день ('to this day') \\
& & DURATION - LIMIT & 0.05 & до рассвета ('until dawn') \\
\hline MANNER & 7.5 & MANNER & 4.75 & порьвисто ('gusty') \\
& & MEANS & 2.15 & на глаз ('to eye') \\
& & SOUND & 0.67 & громко ('loudly') \\
\hline DEGREE & 29.44 & DEGREE & 29.44 & безмерно ('immensely') \\
\hline REASON & 16.58 & REASON & 16.58 & от пота ('with sweat') \\
\hline PURPOSE & 2.33 & PURPOSE & 2.33 & для чая ('for tea') \\
\hline
\end{tabular}

It must be noted that there is one more classification of adjuncts. They can be divided into modifiers of sentences and modifiers of predicates [34]. They are not distinguished in this work. Hence, there are adjuncts of both types in the data set.

Figure 1 represents the correspondence analysis (CA) plot for the class of adjuncts and the parts of speech of the content-word head of the adjunct phrase. The first two dimensions of the CA plot explain ca. $84 \%$ variance. We see that PART (intensifying particles) are strongly associated with DEGREE, whereas S (prepositional phrases), V (gerundive and finite clauses), and ADV (adverbials) are rather neutral. SPRO (mostly personal and demonstrative pronominals) are associated with PURPOSE and PLACE. Other parts of speech are less frequent.

Another CA plot shows most frequent head words of adjuncts associated with the class of adjuncts (Figure 2). TIME is associated with adverbs such as mеnерь ('now'), потом ('later'), тогда ('then'), сейчас ('now') and nouns such as время ('time'), год ('year'), день ('day'), раз ('time'). PLACE is associated with the adverbs там ('there'), здесь ('here'), где ('where'), высоко ('high'). DEGREE is associated with the particles даже ('even') и $и$ ('and'), adverbs сильно ('strongly'), очень ('very'), 


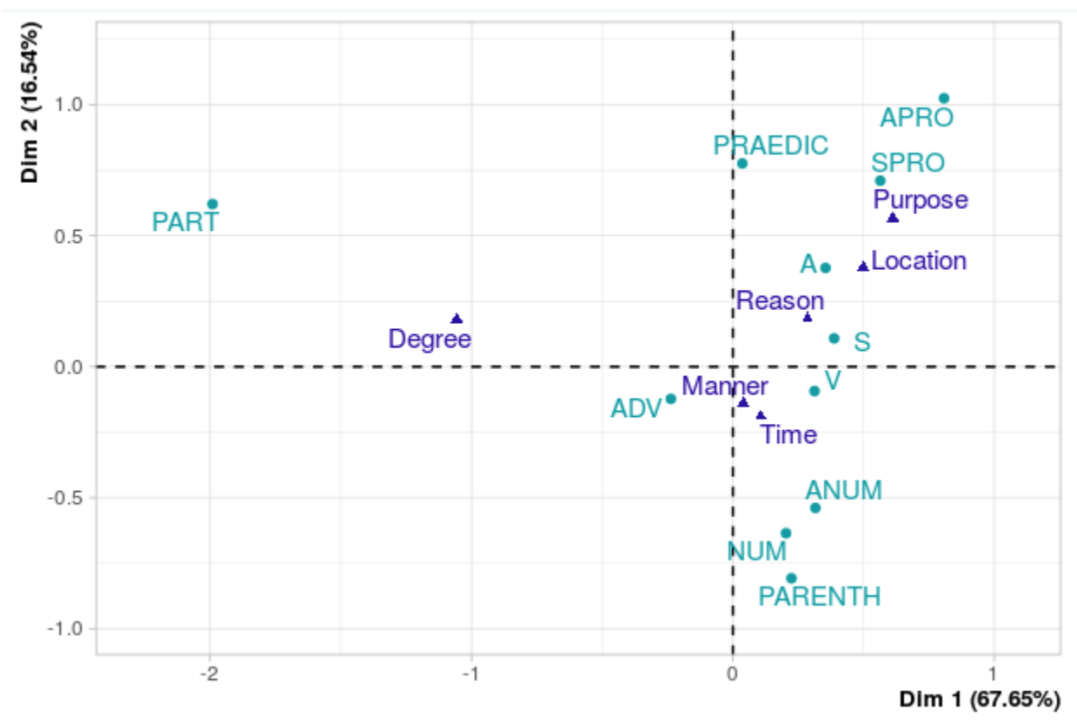

Figure 1. CA map: adjunct class vs. head POS

больше ('more'). MANNER — with the adverbs так ('this way'), как ('how'), просто ('just'). Interestingly, PURPOSE and REASON do not have frequent head words associated with them. REASON is also more neutral, which can indicate that it is associated with words of different classes.

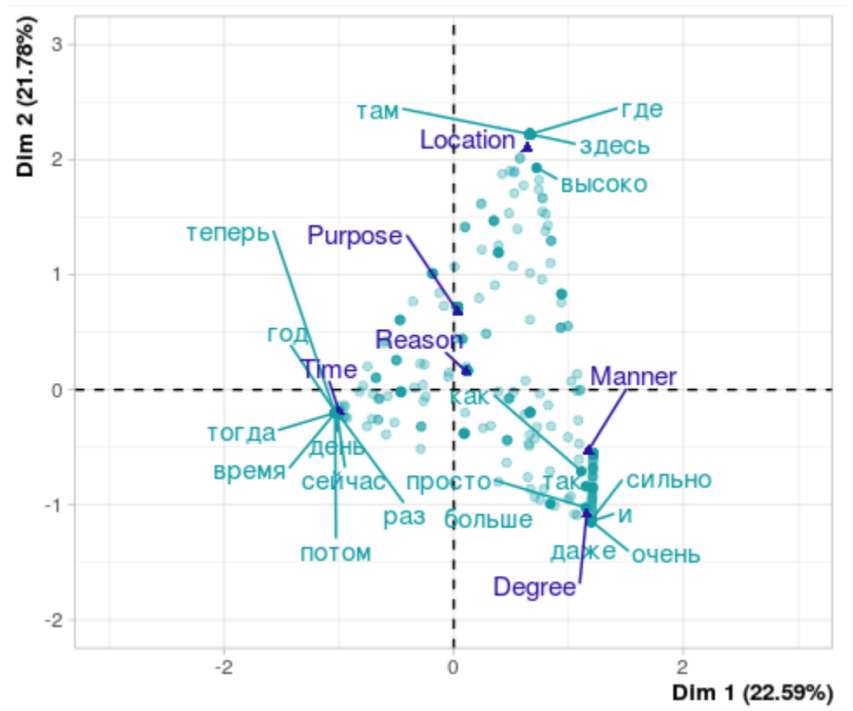

Figure 2. CA map: adjunct class vs. head word

Finally, CA plot on Figure 3 illustrates associations between the most frequent verbs and the class of adjuncts. There are three clusters:

- centered around DEGREE;

- centered around MANNER and PLACE;

- centered around TIME, REASON, and PURPOSE.

We can see some fascinating regularities, but the classifying experiment probably will make them clearer.

\section{Method}

The classifier predicts the role of an adjunct in the input sentence, given three features:

1. a word2vec representation [49] of an (lemmatized) adjunct; if an adjunct consists of more than one word, the program calculates the mean of all meaningful constituents' scores; 


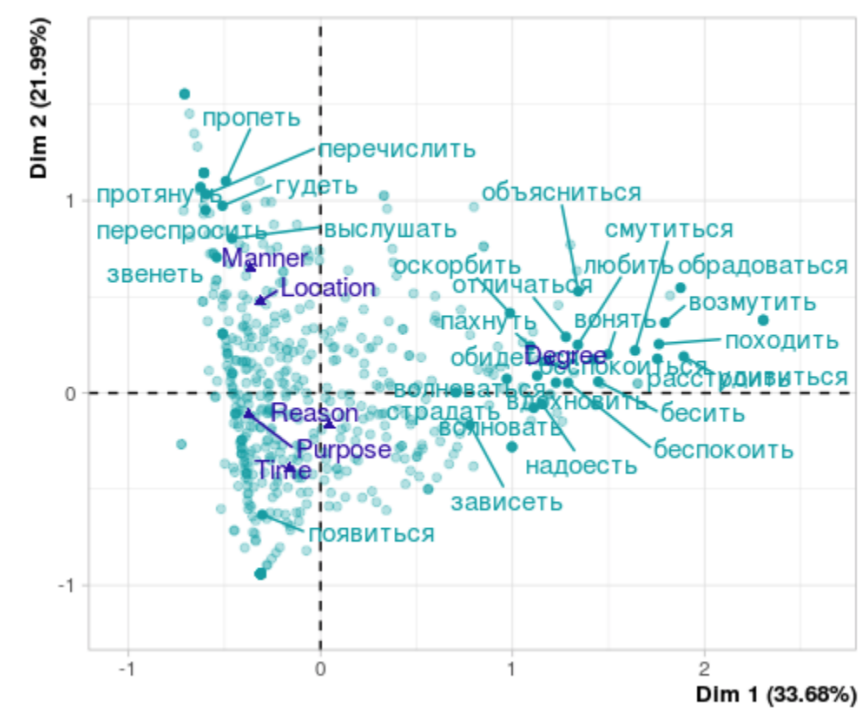

Figure 3. CA map: adjunct class vs. verb

2. a word2vec vector score of a corresponding (lemmatized) predicate;

3. a form (see Section 3); it is a categorical feature, so all forms' types (27) were encoded to lists of 0 and 1 by one-hot encoding.

In this work, a word $2 \mathrm{vec}$ model $^{1}$ was used, pre-trained on Taiga Corpus [40] (about $5 \mathrm{GW}$ ) and supplied with Universal POS Tags. The model architecture was continuous skip-gram, with the vector size of 300 and the context window size of 2 .

Then, after preprocessing, the data were divided into two samples: a training set (80\%) and a test one $(20 \%)$.

We tested four classification models on our data: Decision Tree, Random Forest and two Gradient Boosting models: basic one from Scikit-learn [35] Python library and advanced one from CatBoost [8] Python library. As a baseline, two models were used that choose the most frequent tag for the adjunct (character string) and the adjunct form, respectively. Table 4 represents the quality metrics of these models and the baseline models.

Table 4. Model performance

\begin{tabular}{|l|c|c|c|}
\hline Model & Precision & Recall & Macro F1-score \\
\hline Baseline & - & - & 0.09 \\
Decision Tree & 0.88 & 0.87 & 0.87 \\
Random Forest & $\mathbf{0 . 9 5}$ & 0.89 & 0.91 \\
Gradient Boosting & 0.92 & 0.91 & 0.91 \\
CatBoost & $\mathbf{0 . 9 5}$ & $\mathbf{0 . 9 4}$ & $\mathbf{0 . 9 4}$ \\
\hline
\end{tabular}

The CatBoost model performed best (F1-score is 0.94$)$.

\section{Results}

A summary of the CatBoost model performance on the test set is presented below (Table 5). The macroF1 is 0.94 and micro- and weighted F1 is 0.95 , which indicates the high quality of the model. Whereas the F1-score for the roles of TIME and PLACE is 0.97 and higher, the model performs poorly on the minority class, REASON $(\mathrm{F} 1=0.9)$. It has rather low recall $(0.86)$.

Figure 4 reports on the feature importance metric calculated on the CatBoost and Random Forest models. Surprisingly, the adjunct word2vec feature emerges as more important than the two others used in

\footnotetext{
${ }^{1}$ The model was taken from RusVectōēs (URL: https ://rusvectores .org/ru/models/).
} 
Table 5. Detailed metrics of the CatBoost model

\begin{tabular}{|l|c|c|c|}
\hline & Precision & Recall & Macro F1-score \\
\hline PLACE & 0.94 & 0.97 & 0.96 \\
TIME & 0.98 & 0.98 & 0.98 \\
MANNER & 0.92 & 0.95 & 0.93 \\
DEGREE & 0.97 & 0.93 & 0.95 \\
PURPOSE & 0.95 & 0.95 & 0.95 \\
REASON & 0.94 & 0.86 & 0.90 \\
\hline Macro average & 0.95 & 0.94 & 0.94 \\
Weighted average & 0.95 & 0.95 & 0.95 \\
\hline
\end{tabular}

both model. However, importance of the form feature is different ( 0.098 for CatBoost and 0.022 for Random Forest). Probably, it is because the CatBoost algorithm handles categorical data better than other algorithms with one-hot encoding. Perhaps it is the main reason why the CatBoost model performed better than others.

Random Forrest

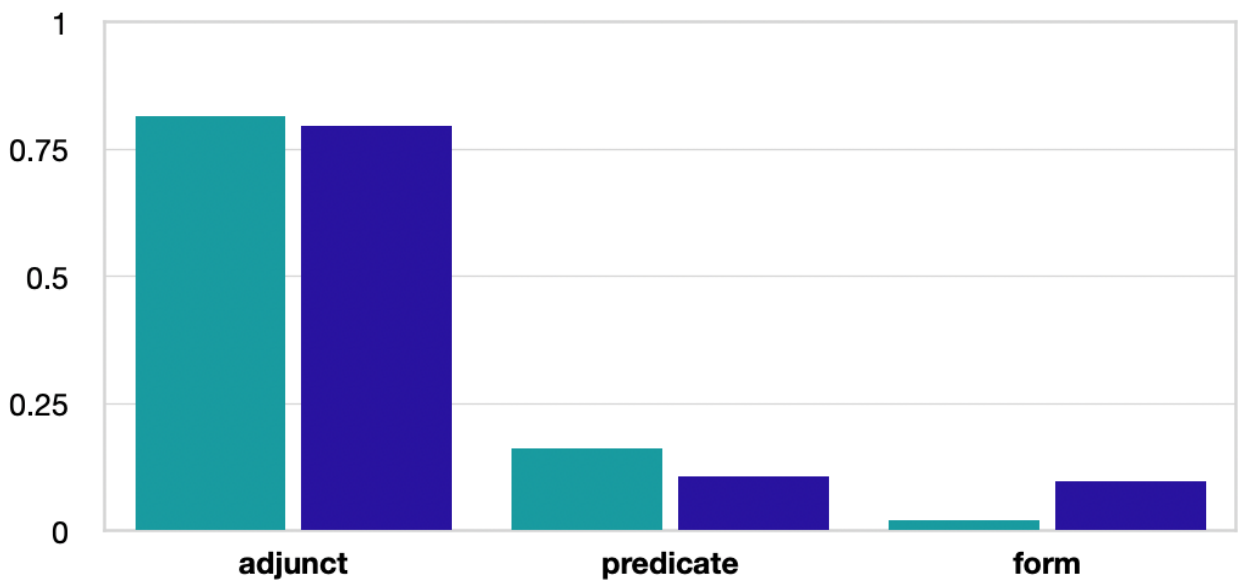

Figure 4. Feature importance of the CatBoost and Random Forest models

\section{Analysis}

It turned out that the adjunct word $2 \mathrm{vec}$ feature is the most important feature. This indicates that adjuncts by themselves are strongly associated with certain semantic roles and, to some extent, semantically independent of the predicates. Furthermore, the word $2 \mathrm{vec}$ vector score of a predicate feature is relatively low (hereinafter the CatBoost model: 0.106), but not around zero, and this confirms that adjuncts do not fill in semantic valencies of predicates, though at the same time adjuncts may not be used with any predicate. Perhaps this depends on the type of adjunct.

The lowest F1-score was shown by the group of REASON adjuncts $(F 1=0.9)$. Interestingly, there is a wide gap between precision and recall. This means that the classifier leaves a lot of true negatives and some types resemble them. This is most likely due to the heterogeneity of REASON adjuncts and the small amount of them in our data sample (only 132 elements in the test set). In addition, adjuncts of REASON and PURPOSE are often longer than others (they are expressed sometimes by subordinate clauses). By contrast, temporal adjuncts performed almost perfectly (the F1-score is 0.98 ) due to their semantic similarity. Thus, more homogeneous types demonstrate better results. This situation had been described in detail via a correspondence analysis: it presented three distinct clusters including temporal, 
locative, manner and degree adjuncts (Figure 2). It is noteworthy that higher results were expected from locative adjuncts (the F1-score is 0.96 ), because this type seemed to be extremely detached.

PLACE, MANNER, REASON are classes that have the lowest precision: it seems that the word2vec embeddings models are not confident enough to distinguish metaphorical shifts, e.g. assigning PLACE to adverbs used in temporal meaning (cf. здесь 'here, in this moment') and MANNER to adverbs used as intensifiers (cf. нежно 'gently, slightly').

Besides that, the lemmatized word2vec models are content words-biased and fail to identify cases in which the semantics of the preposition and other closed-class words shifts the interpretation of the whole phrase (e.g. минуту 'for a minute', TIME - ради такой минутьы 'for the sake of such a moment', PURPOSE).

\section{Discussion}

Considering the feature importance metrics, it may seem like the representation of an adjunct is the only significant feature, but it is not. There are some examples (под бомбами 'under the bombs' - PLACE) where meaningful words do not refer to the type of the adjunct. Such cases provide the idea that form and predicate also affect the final prediction of the classifier.

\section{Conclusion}

In this work, we performed the labeling experiments for Russian adjuncts with rather high efficiency (average F1-score is 0.94). The proposed method can further be implemented in the SRL systems to classify elements that are not core arguments of the predicate. Owing to its interpretability, it promises to be helpful, in different areas, for example, information retrieval, information extraction, QA-systems, and automatic translation.

The word2vec representations of adjuncts turned out to be a powerful effect in the task. Contextual embeddings and/or syntactic features are obvious candidates to be added to the model in order to improve its quality and ensure more accurate labeling of long adjuncts.

The theoretical assumptions that adjuncts do not fill in semantic slots of predicates based on the distinction of arguments and adjuncts are confirmed for the most part. Adjuncts demonstrate high independence from predicates, but apparently it is not an absolute truth.

\section{References}

[1] Alimova I., Tutubalina E., Kirillovich A. Cross-lingual Transfer Learning for Semantic Role Labeling in Russian // Fourth International Conference Computational Linguistics in Bulgaria. 2019. - P. 72.

[2] Apresyan Yu. D. Lexical semantics [Leksicheskaya semantika]. - 2 edition. - Moscow : Yazyki russkoj kul'tury, 1995.

[3] Baker C. F., Fillmore C. J., Lowe J. B. The Berkeley FrameNet Project // 36th Annual Meeting of the Association for Computational Linguistics and 17th International Conference on Computational Linguistics, Volume 1. - Montreal, Quebec, Canada : Association for Computational Linguistics, 1998. - P. 86-90. - Access mode: https://www. aclweb.org/anthology/P98-1013.

[4] Boguslavsky I. M. Scope of lexical units [Sfera dejstviya leksicheskih edinic]. - Moscow : Shkola "Yazyki russkoj kul'tury", 1996.

[5] Cinque G. Adverbs and Functional Heads: A Cross-Linguistic Perspective. - Oxford : Oxford University Press, 1999.

[6] The Compreno Semantic Model as Integral Framework for Multilingual Lexical Database / E. Manicheva, M. Petrova, E. Kozlova, T. Popova // Proceedings of the 3rd Workshop on Cognitive Aspects of the Lexicon. - Mumbai, India : The COLING 2012 Organizing Committee, 2012. Dec. - P. 215-230. - Access mode: https://www. aclweb.org/anthology/W12-5117.

[7] Deep Semantic Role Labeling with Self-Attention / Zh Tan, M. Wang, J. Xie et al. // CoRR. 2017. - Vol. abs/1712.01586. - 1712.01586. 
[8] Dorogush A. V., Ershov V., Gulin A. CatBoost: gradient boosting with categorical features support. - 2018. - 1810.11363.

[9] Ernst T. The Syntax of Adjuncts. - Cambridge University Press, 2001. - Vol. 96 of Cambridge Studies in Linguistics.

[10] Filipenko M. V. Adverbs in "Lexicograph" system // Computational Linguistics and Intellectual Technologies: Proceedings of the International Conference "Dialog 2004" [Komp'yuternaya Lingvistika i Intellektual'nye Tekhnologii: Trudy Mezhdunarodnoy Konferentsii “Dialog 2004”]. - Moscow : Nauka, 2004. - P. 650-655.

[11] Generalized Inference with Multiple Semantic Role Labeling Systems / P. Koomen, V. Punyakanok, D. Roth, W. Yih // Proceedings of the Ninth Conference on Computational Natural Language Learning (CoNLL-2005). - Ann Arbor, Michigan : Association for Computational Linguistics, 2005. P. 181-184. - Access mode: https://www.aclweb.org/anthology/W05-0625.

[12] Gildea D., Jurafsky D. Automatic Labeling of Semantic Roles // Computational Linguistics. 2002. - Vol. 28, no. 3. - P. 245-288. - Access mode: https://www. aclweb.org/anthology/ J02-3001.

[13] Interfacing the Lexicon and the Ontology in a Semantic Analyzer / I. Boguslavsky, L. Iomdin, V. Sizov, S. Timoshenko // Proceedings of the 6th Workshop on Ontologies and Lexical Resources. - Beijing, China : Coling 2010 Organizing Committee, 2010. - P. 67-76. - Access mode: https://www . aclweb. org/anthology/W10-3308.

[14] Jackendoff R. Semantic interpretation in generative grammar Cambridge // MA: MIT. - 1972.

[15] Kashkin E. V., Lyashevskaya O. N. Semantic roles and construction net in Russian FrameBank [Semanticheskie roli i set'konstrukcij v sisteme FrameBank] // Computational Linguistics and Intellectual Technologies: Proceedings of the International Conference "Dialog" [Komp'yuternaya Lingvistika i Intellektual'nye Tekhnologii: Trudy Mezhdunarodnoy Konferentsii "Dialog"]. - Vol. 12. 2013. - P. 1.

[16] Khrakovsky V. S. Consept of adjunct and its status [Ponjatie sirkonstanta i ego status] // Semiotika i informatika. - 1998. - Vol. 36. - P. 141-153.

[17] Khrakovsky V. S. Verbocentric approach to constructions and/or Construction Grammar [Verbotcentricheskij podkhod k konstruktsijam i/ili grammatika konstrukcij] // Smysly, teksty i drugie zakhvatyvajuschie sjuzhety. Sbornik statej v chest' 80-letija I. A. Mel'čuka. - 2012. - P. 288-300.

[18] Kuznetsov I. Semantic Role Labeling for Russian Language Based on Russian FrameBank // Analysis of Images, Social Networks and Texts / Ed. by M. Yu. Khachay, N. Konstantinova, A. Panchenko et al. - Cham : Springer International Publishing, 2015. - P. 333-338.

[19] Kuznetsov I. Automatic semantic role labelling in Russian language, $\mathrm{PhD}$ thesis : Ph.D. thesis / I. Kuznetsov ; Higher School of Economics. - Moscow, 2016.

[20] Lang J., Lapata M. Unsupervised Semantic Role Induction with Graph Partitioning // Proceedings of the 2011 Conference on Empirical Methods in Natural Language Processing. - Edinburgh, Scotland, UK. : Association for Computational Linguistics, 2011. - P. 1320-1331. - Access mode: https://www. aclweb.org/anthology/D11-1122.

[21] Lazard G. L'Actance. - Paris : Presses Universitaires de France, 1994.

[22] Learning Structured Natural Language Representations for Semantic Parsing / J. Cheng, S. Reddy, V. Saraswat, M. Lapata // Proceedings of the 55th Annual Meeting of the Association for Computational Linguistics (Volume 1: Long Papers). - Vancouver, Canada : Association for Computational Linguistics, 2017. - P. 44-55. - Access mode: https://www . aclweb.org/anthology/P17-1005.

[23] Linguistic Encyclopedic Dictionary [Lingvisticheskij enciklopedicheskij slovar'] / Ed. by V. N. Yartseva. - Moscow : Sovetskaya enciklopediya, 1990.

[24] Linguistically-Informed Self-Attention for Semantic Role Labeling / E. Strubell, P. Verga, D. Andor et al. // Proceedings of the 2018 Conference on Empirical Methods in Natural Language Processing. - 
Brussels, Belgium : Association for Computational Linguistics, 2018. - P. 5027-5038. - Access mode: https://www. aclweb.org/anthology/D18-1548.

[25] Llorens H., Saquete E., Navarro-Colorado B. Automatic system for identifying and categorizing temporal relations in natural language // International Journal of Intelligent Systems. - 2012. - Vol. 27, no. 7. - P. 680-703. - https://onlinelibrary.wiley.com/doi/pdf/10.1002/int.21542.

[26] Lyashevskaya O. N., Kashkin E. V. FrameBank: A Database of Russian Lexical Constructions // Analysis of Images, Social Networks and Texts / Ed. by M. Yu. Khachay, N. Konstantinova, A. Panchenko et al. - Cham : Springer International Publishing, 2015. - P. 350-360.

[27] Maienborn C., Schäfer M. Adverbs and adverbials // Semantics: Lexical Structures and Adjectives / Mounton de Gruyter. - 2019. - P. 477-514.

[28] Munir K., Zhao H., Li Z. Adaptive Convolution for Semantic Role Labeling // IEEE/ACM Transactions on Audio, Speech, and Language Processing. - 2021. - Vol. 29. - P. 782-791.

[29] Palmer M., Gildea D., Kingsbury P. The Proposition Bank: An Annotated Corpus of Semantic Roles // Comput. Linguist. - 2005. - Mar. - Vol. 31, no. 1. - P. 71-106. - Access mode: https: //doi.org/10.1162/0891201053630264.

[30] Palmer M., Gildea D., Xue N. Semantic Role Labeling // Synthesis Lectures on Human Language Technologies. - 2010. - Vol. 3, no. 1. - P. 1-103. — https://doi.org/10.2200/S00239ED1V01Y200912HLT006.

[31] Petrova M. The Compreno Semantic Model: The Universality Problem // International Journal of Lexicography. - 2013. - 05. - Vol. 27. - P. 105-129.

[32] Plungian V. A., Rakhilina E. V. The valence paradoxes // Semiotika i informatika. - 1998. - Vol. 36.

[33] The Russian PropBank / S. Moeller, I. Wagner, M. Palmer et al. // Proceedings of the 12th Language Resources and Evaluation Conference. - Marseille, France : European Language Resources Association, 2020. - P. 5995-6002. - online; accessed: https://www.aclweb.org/anthology/ 2020. lrec-1.734.

[34] Russian grammar [Russkaya grammatika] / Ed. by N. Yu. Shvedova. - Moscow : Nauka, 1980. Vol. 2.

[35] Scikit-learn: Machine Learning in Python / F. Pedregosa, G. Varoquaux, A. Gramfort et al. // Journal of Machine Learning Research. - 2011. - Vol. 12. - P. 2825-2830.

[36] Semantic Role Labeling For Russian Language Based on Ensemble Model / X. Zheng, B. Zhou, J. Huang et al. // 2019 IEEE 8th Joint International Information Technology and Artificial Intelligence Conference (ITAIC). - 2019. - P. 1263-1268.

[37] Semantic Role Labeling with Pretrained Language Models for Known and Unknown Predicates / D. Larionov, A. Shelmanov, E. Chistova, I. Smirnov // Proceedings of the International Conference on Recent Advances in Natural Language Processing (RANLP 2019). - Varna, Bulgaria : INCOMA Ltd., 2019. - Sep. - P. 619-628. - Access mode: https://www.aclweb.org/anthology/ R19-1073.

[38] Semeval-2013 task 1: Tempeval-3: Evaluating time expressions, events, and temporal relations / N. UzZaman, H. Llorens, L. Derczynski et al. // Second Joint Conference on Lexical and Computational Semantics (* SEM), Volume 2: Proceedings of the Seventh International Workshop on Semantic Evaluation (SemEval 2013). - 2013. - P. 1-9.

[39] Semeval-2015 task 8: Spaceeval / J. Pustejovsky, P. Kordjamshidi, M.-F. Moens et al. // Proceedings of the 9th International Workshop on Semantic Evaluation (semeval 2015) / ACL. - 2015. - P. 884894.

[40] Shavrina T., Shapovalova O. To the methodology of corpus construction for machine learning:"Taiga" syntax tree corpus and parser // Proceedings of "CORPORA-2017" International Conference. - 2017. - P. 78-84.

[41] Shelmanov A., Smirnov I. Methods for semantic role labeling of Russian texts // Computational Linguistics and Intellectual Technologies: Proceedings of the International Conference "Dialog 2014" 
[Komp'yuternaya Lingvistika i Intellektual'nye Tekhnologii: Trudy Mezhdunarodnoy Konferentsii "Dialog 2014"]. - 2014. - P. 607-619.

[42] Shelmanov A. O., Devyatkin D. A. Semantic role labeling with neural networks for texts in Russian // Computational Linguistics and Intellectual Technologies: Proceedings of the International Conference "Dialog" [Komp'yuternaya Lingvistika i Intellektual'nye Tekhnologii: Trudy Mezhdunarodnoy Konferentsii "Dialog"]. - 2017. - P. 245-256.

[43] Sokirko A. V. Semantic Dictionaries in the Natural Language Processing: Based on the DIALING system [Semanticheskie slovari v avtomaticheskoj obrabotke teksta: Po materialam sistemy DIALING] // Cand. Tech. Sc. Dissertation. - Moscow, 2001.

[44] Sun H., Jurafsky D. Shallow Semantic Parsing of Chinese // Proceedings of the Human Language Technology Conference of the North American Chapter of the Association for Computational Linguistics: HLT-NAACL 2004. - Boston, Massachusetts, USA : Association for Computational Linguistics, 2004. - P. 249-256. - Access mode: https://www.aclweb.org/anthology/ N04-1032.

[45] Syntactic And Semantic Parser Based On Abbyy Compreno Linguistic Technologies / V. P. Selegej, K. V. Anisimovich, F. R. Minlos et al. // Computational Linguistics and Intellectual Technologies: Proceedings of the International Conference "Dialog 2012" [Komp'yuternaya Lingvistika i Intellektual'nye Tekhnologii: Trudy Mezhdunarodnoy Konferentsii "Dialog 2012"]. - Vol. 2. 2012. - P. 91-103.

[46] Syntax for Semantic Role Labeling, To Be, Or Not To Be / Sh. He, Z. Li, H. Zhao, H. Bai // Proceedings of the 56th Annual Meeting of the Association for Computational Linguistics (Volume 1: Long Papers). - Melbourne, Australia : Association for Computational Linguistics, 2018. - P. 20612071. - Access mode: https://www. aclweb.org/anthology/P18-1192.

[47] Tesnière L. Elements of Structural Syntax [Eléments de syntaxe structurale]. - Paris : Klincksieck, 1959.

[48] Testelets Ya. G. Introduction to general syntax [Vvedenie v obshchij sintaksis]. - Moscow : Rossijskij gosudarstvennyj gumanitarnyj universitet, 2001. - P. 156-228.

[49] word2vec / T. Mikolov, K. Chen, G. Corrado et al. // URL https://code.google.com/p/word2vec. 2013. - Vol. 22. 